\title{
A COMBINATION PROSTHESIS USING THIMBLE COPINGS FOR RECONSTRUCTION OF MUTILATED DENTITION: A CASE REPORT AT NOBEL MEDICAL COLLEGE, BIRATNAGAR
}

Warainch $\mathrm{RS}^{1^{*}}$, Dali $\mathrm{M}^{2}$, Naulakha $D^{3}$

\section{Affiliation}

1. Lecturer, Department of Prosthodontics, Nobel Medical College and Teaching Hospital, Nepal

2. Associate professor, Department of Pedodontics and Preventive Dentistry, CODS, BPKIHS, Nepal

3. Assistant Professor, Department of Conservative Dentistry, Nobel Medical College and Teaching Hospital, Nepal

\section{ARTICLE INFO}

\section{Article History}

Received : 11 March, 2017

Accepted : 14 July, 2017

Published : 30 August, 2017

(C) Authors retain copyright and grant the journal right of first publication with the work simultaneously licensed under Creative Commons Attribution License CC - BY 4.0 that allows others to share the work with an acknowledgment of the work's authorship and initial publication in this journal.

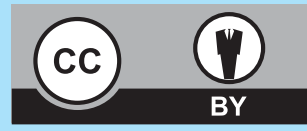

\section{CR 8}

\section{* Corresponding Author}

Dr Robin Singh Warainch

Lecturer, Department of Prosthodontics

Nobel Medical College and Teaching Hospital, Nepal

Email: emailorobinsingh@gmail.com

\begin{abstract}
Planning and executing the restorative rehabilitation of a severely mutilated dentition is one of the most challenging tasks for the restorative dentist. This case report illustrates an interdisciplinary approach in the treatment of a multifaceted case of partial loss of teeth. A series of provisional prosthesis were used before the final treatment due to extreme complexity of the patient situation. The final treatment was composed of innovatively designed thimble copings, telescopic retainer and cast metal frame work for the rehabilitation of the maxillary and mandibular arch.
\end{abstract}

\section{KEY WORDS}

Prosthesis, restorative, telescopic, thimble

\section{Citation}

Warainch RS, Dali M, Naulakha D A Combination Prosthesis Using Thimble Copings for Reconstruction of Mutilated Dentition: A Case Report at Nobel Medical College, Biratnagar BJHS 2017;2 (2)3:222-226 


\section{INTRODUCTION}

The partial loss of dentition can lead to various problems in the masticatory system of the patient which can be functional, biological and aesthetical. ${ }^{1,2}$ This can lead to minor or major movements of the left out teeth in the arch and loss of vertical dimension of occlusion (VDO) can occur by supra eruption of the opposing teeth. ${ }^{2,3}$

This clinical report demonstrates an interdisciplinary approach in treatment planning of a complex case of partial edentulism. Due to extreme complexity of the patient's intra oral situation, the final treatment was accomplished after series of provisional prosthesis. The final treatment involved innovatively designed thimble copings and telescopic crowns as retainers for fixed removable prosthesis that uses the concept of telescopic attachments and takes support from the fixed retainers as well as remaining teeth as abutments thus making it hybrid prosthesis.

\section{CASE REPORT}

A 52 year old partially edentulous male patient reported to the Department of Prosthodontics for the management of complex intra oral dental situation. In his chief complaint patient said that he was unhappy with his dental condition as it affected his quality of life. The patient wanted better esthetics, feasible and affordable treatment plan which would enable him to eat better and provide satisfactory esthetics.

Intra orally, the prominent features were as follows: the patient had undergone mandibular fixed prosthesis treatment few years back, which had dislodged and the patient was not more using it from past few months, partially edentulous maxillary arch with missing 15, 16,17 and partially edentulous mandibular arch with missing teeth as follows 31, 37, 46 and 47 (Figure 1).

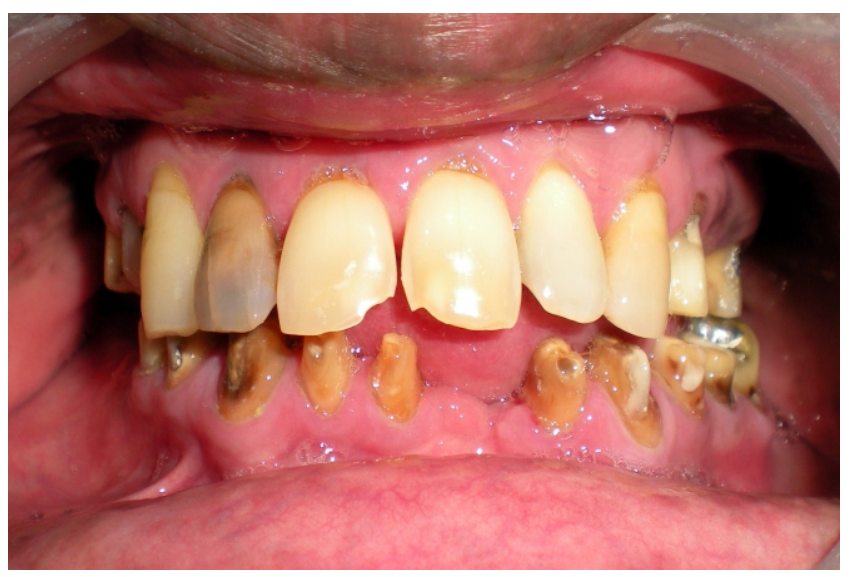

Figure 1: Preoperative view

None of the teeth were mobile. The tooth 47 had silver amalgam restorations. In the maxillary arch 12 had arrested caries, 16, 24 and 25 had composite restorations and core built up done. Measuring the vertical dimension of occlusion (VDO) revealed increase in freeway space $(6 \mathrm{~mm})$. Radiographic assessment indicated minimal bone loss around the abutment teeth and increase alveolar bone loss bilaterally in the maxillary arch. No periapical pathology was revealed and there was no sign of temperomandibular disorder.

The patient was stabilized by oral hygiene measures and oral hygiene instructions were emphasized before considering any rehabilitative treatment.

After obtaining the study casts, anterior deprogramming device was used to deprogram the oral musculature and intra oral bite registration using bite registration material (Imprint, 3M ESPE, USA) was taken in centric relation position. The face-bow was used to articulate the diagnostic casts to a semi adjustable articulator (Whip Mix Corporation, USA), using bite registration which was previously obtained. Subsequently, it was possible to assess the potential treatment options closely and any adjunctive procedure required.

The Unilateral group function occlusion scheme was planned on the principles of biological occlusion described by Becker and Kaiser ${ }^{3}$ but due to loss of tooth structure of both mandibular canines, the occlusion scheme was changed to bilateral group function.

The treatment options presented were:

- Maxillary arch restoration with fixed partial denture.

- Mandibular arch rehabilitation with combination prosthesis using thimble coping and crowns on all the natural teeth remaining and followed by a fixed removable prosthesis which used a cast partial denture like framework in the edentulous area. ${ }^{4}$

\section{Definitive treatment planning:}

All possible treatment options and outcomes were discussed with the patient. Despite the patients preference for a fixed partial denture for mandibular arch, hybrid fixed removable prosthesis using telescopic retainers was chosen to facilitate greater home care and oral hygiene measures as patient had compromised periodontal status in mandibular arch due to poor oral hygiene.

\section{Prosthetic rehabilitation of Maxillary arch:}

Tooth preparations of 14, 16, 17, 24, 25 and 27 were modified, followed by gingival retraction and impression was made

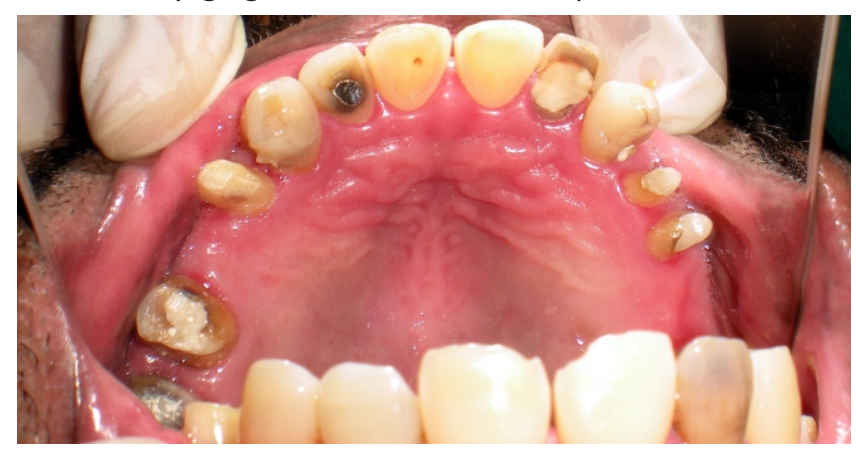

Figure 2: Tooth preparations of 14, 16, 17, 24, 25, 27

using polyvinyl siloxane impression material (Reprosil, Dentsply India). (Figure 2)

Heat cure provisional restorations (DPI heat cure tooth molding powder, Dental products of India, Mumbai) were fabricated according to the diagnostic wax up and were 
cemented with temporary cement (Rely X Temp NE, 3M ESPE products). The face bow was used to articulate the maxillary cast on a semi adjustable articulator.

\section{Rehabilitation of Mandibular arch:}

In the mandibular arch tooth preparations were refined and modified wherever possible to receive cast metal copings. Excessive modifications to the tooth preparations could not be done due to loss of tooth structure in previous fixed partial denture prosthesis (Figure 3). Following gingival retraction, impression of mandibular arch was made using polyvinyl siloxane impression material (Reprosil, Dentsply India). Heat cured provisional restorations (DPI heat cure tooth molding powder, DPI, India) was fabricated and tried on semi adjustable articulator and adjusted to Bilateral Group

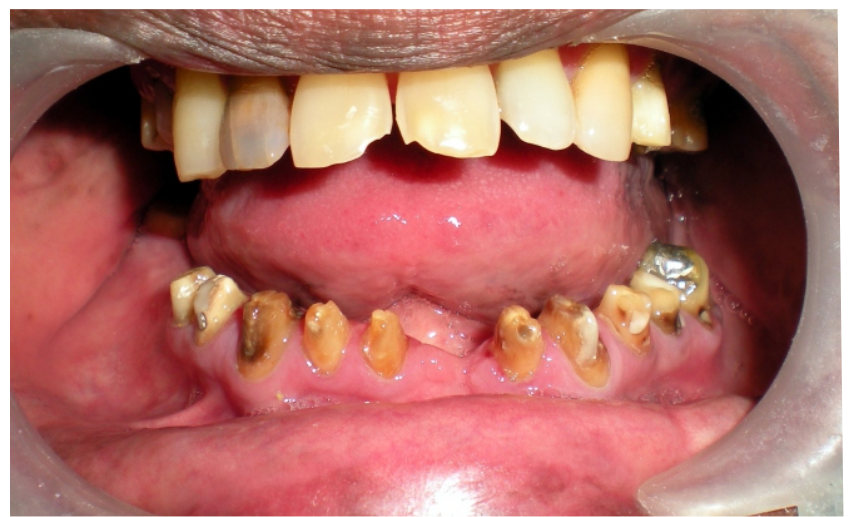

Figure 3: Tooth preparations of 32, 33, 34, 38, 41, 42,43, 44, 45, 46

Function scheme. It was checked intra orally in the patient's mouth and necessary corrections were done.

Madibular cast was obtained and articulated to the semi adjustable articulator using intra oral bite registration which was obtained using bite registration material in centric occlusion.

During the modifications of tooth preparations it was taken care that tooth preparations were modified to achieve near parallel axial walls wherever possible. This is because parallel the walls of the coping, the greater mechanical friction interlocking of the coping with the overlying crown. The parallel axial walls of short teeth offer better resistance form. ${ }^{5}$ Grooves were prepared in buccal and lingual walls of the abutments to achieve more retention. Wax pattern were fabricated with cervical shoulder, surveyed to check their parallelism and were cast in chrome cobalt alloy. Cast coping

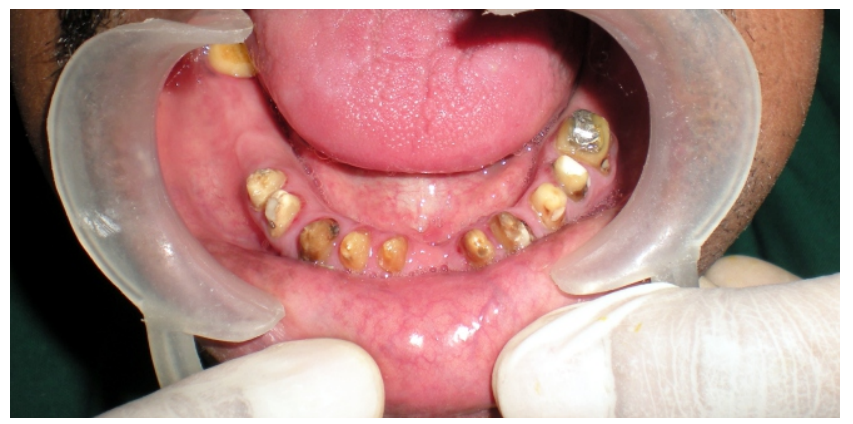

Figure 4: Cemented coping were also surveyed to check the parallelism and determine most suitable path of insertion of the definitive prosthesis. After required adjustments, coping were cemented using GIC (FUGI, GC Corporation, Tokyo, Japan). (Figure 4)

Final impressions were made to record the anatomical details of the metal copings. The mandibular master cast was obtained from this impression and was then duplicated in reversible hydrocolloid duplicating material (WiroGel $M$, Bego, Germany) to obtain the refractory cast for the fabrication of cast metal framework. Intra oral bite record was used to articulate the maxillary cast against mandibular refractory cast. The definitive waxing for mandibular cast metal framework was performed along with wax up for copings for over crowns (PFM) on 32, 33, 34, 38, 41, 42, 43, $44,45,46$. A metal try in was performed to verify intra oral fit, retention and stability.

Ceramic facing crowns were fabricated with buccal half ceramic and lingual half metal and to receive half over crown on $35,38,46$ and removable partial denture framework on 36,37 and 47 with cobalt chrome framework.
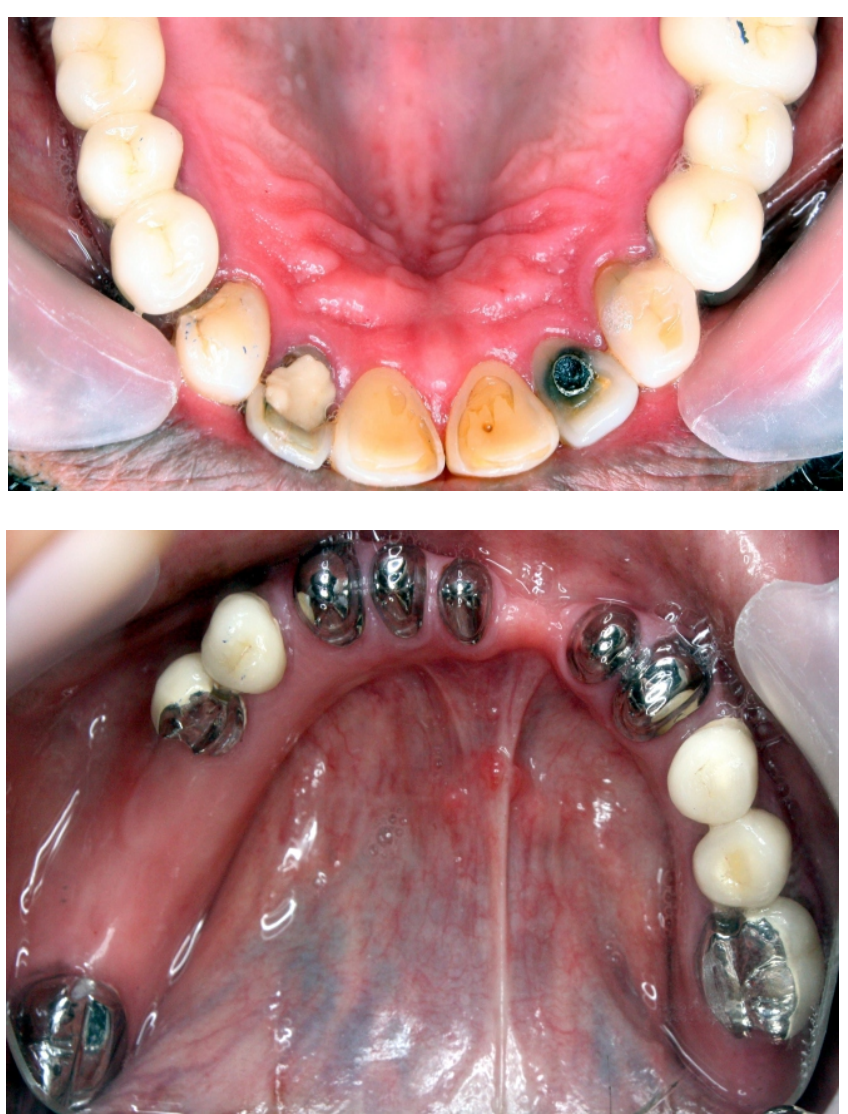

Figure 5a \& 5b: Cobalt chrome framework

The cobalt chrome framework was highly polished after final glazing of porcelain fused to metal crowns and occlusion was adjusted on the articulator and conferred to bilateral group function. (Figure $5 \mathrm{a}, \mathrm{b})$ The maxillary fixed prosthesis was cemented using GIC (FUGI I, GC corporation, Tokyo, Japan). (Figure 6a, 6b) 

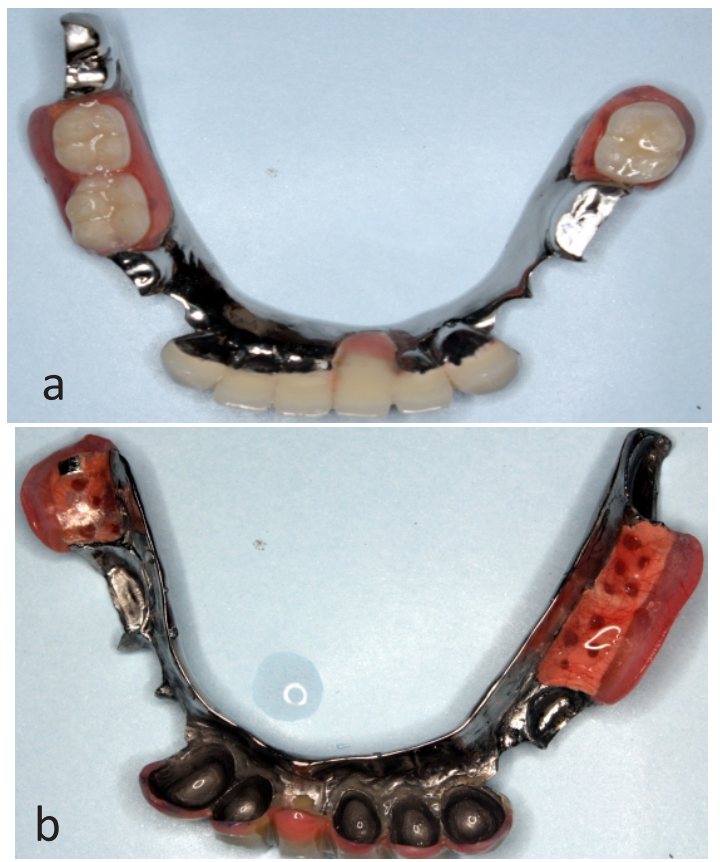

Figure 6a \& 6b: Cementation of fixed prosthesis on maxilla

The mandibular definitive prosthesis was checked intra orally in patient's mouth and intra oral fit, retention stability and occlusion was verified. (Figure 7a, b) Instructions were given to the patient regarding using prosthesis and for regular cleaning of the prosthesis at night and oral hygiene instructions were emphasized. The patient is being followed up regularly and is satisfied with the performance of the prosthesis. There is no complaint of any pain or discomfort in TMJ region.
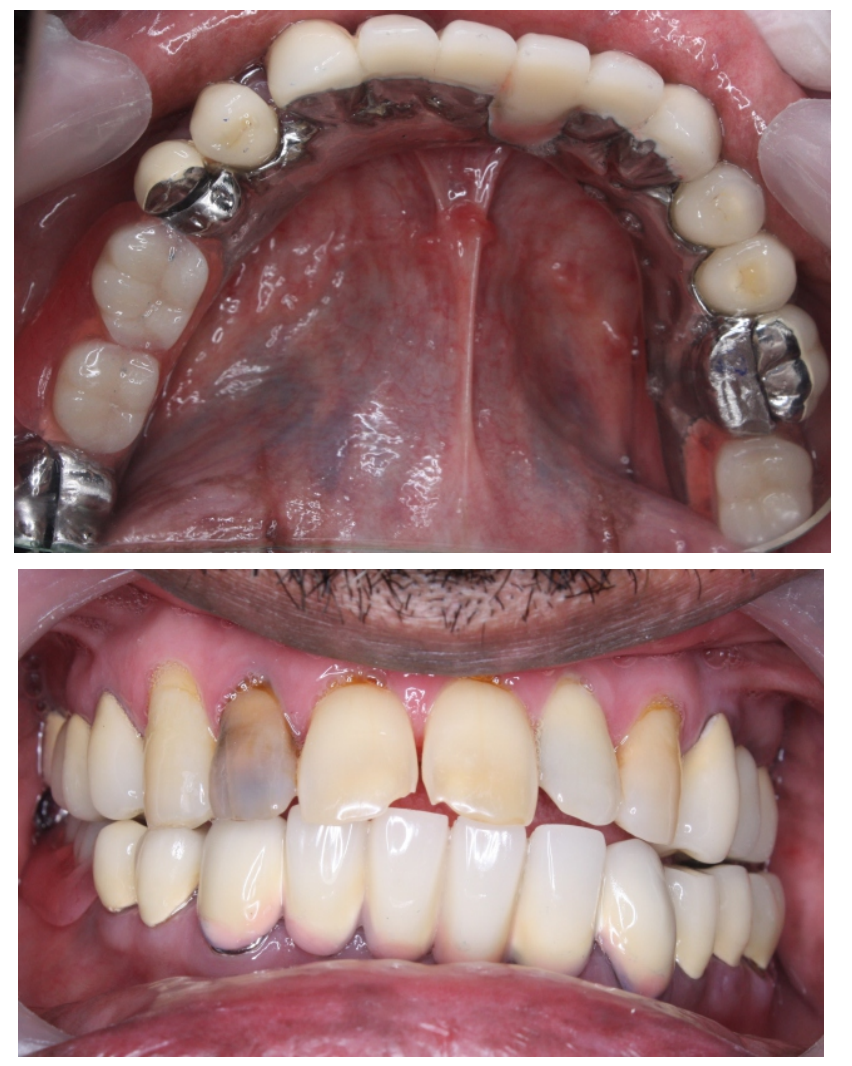

Figure 7a \& 7b: Post Operative View

\section{DISCUSSION}

The reconstruction of a severely mutilated dentition is very complex and difficult problem for the restorative dentist. A wide range of restorative treatment options are possible with today's materials and techniques. A fixed removable prosthesis using telescopic crown retainers was taken as treatment option for this patient. This design involves an inter surface friction during the insertion and removal of the super structure as two parts engage and disengage themselves. ${ }^{6,7}$ Also, this design maintains the integrity of the arch by keeping all the healthy teeth in the arch as abutments for the copings. This gives the patient a prosthesis that has far more support than any conventional prosthesis. Instead of soft, movable mucous membrane, the prosthesis literally sits on teeth "piling", enabling the prosthesis to withstand a much greater occlusal load without movement. ${ }^{8}$ The telescopic overdenture consists of a primary coping or inner telescope, permanently cemented to the abutment tooth and a congruent secondary or outer crown, rigidly anchored in the removable prosthesis. The secondary crown engages the primary coping to form a telescope retainer unit. The coping protects the abutment tooth from caries and thermal irritations and provides the basic element for retention and stabilization of outer part. The secondary crown, being an integral part of the removable prosthesis serves as its anchor with the rest of the dentition. ${ }^{8,9,10,11,12}$ The implant supported prosthesis was other treatment option discussed with the patient. As the implant based prosthesis offers a lot of advantages in the shape of improved retention, more stability and support, low bone loss, better esthetics but the higher cost of the prosthesis had restrained the patient from opting for it..$^{13}$ And also this type of design of prosthesis facilitates easy removal and insertion of prosthesis which makes home care and cleaning of the prosthesis relatively easy for the patient. So, integration of fixed and removable prosthodontics was planned for this patient. A multidisciplinary approach was taken to rehabilitate the patient's mutilated dental status in an organized way. The successful integration of fixed and removable prosthodontics has resulted in accurately fitting, esthetically pleasing and functionally efficient prosthesis. Periodic follow up and meticulous prosthesis maintenance by the patient will hold the key for the ultimate success of these types of rehabilitation procedures.

\section{CONCLUSION}

The successful rehabilitation of the present patient's intra oral situation stresses the importance of judicious use of prosthodontic principles and accurate treatment planning in addition to team work between the specialties of the dentistry. The optimal and esthetically pleasant occlusion was achieved in the present case although there was severe disfigurement of the occlusal plane. This complex looking fixed-removable prosthesis not only restored the patient's esthetics desires but also offered added advantage of being removable so that patient can perform better oral hygiene measures and thus prolonging the life of span of prosthesis and the abutments. 


\section{REFERENCES}

1. EckertSE. Sequelae of partial edentulism. Int J Prosthodont 2007; 20:356.

2. Turner KA, Missirlian DM. Restoration of the extremely worn dentition. J Prosthet Dent 1984; 52:467-474.

3. Becker CM, Kaiser DA. Evolution of occlusion and occlusion instruments. J Prosthodont1993; 2:33-43.

4. Emtiaz S, Tarnow DP. Processed acrylic resin provisional restoration with lingual cast metal framework. J Prosthet Dent 1998; 79:484-488.

5. Langer A. Telescopic retainers and their clinical application. J Prosthet Dent1980; 44:516-532.

6. Yalisove, IL,Dietz, JR: Telescopic Prosthetic therapy. Philadelphia, George F Stickley Co., 1977, 11p.

7. Weigl P, Hahn L, Lauer HC: Advanced biomaterials used for a new telescopic retainers for removable dentures. J Biomed Matu Res 2000; 53:320-336.
8. DeFranco RL. Overdentures. In:Winkler S(Ed). Essentials of complete denture Prosthodontics ( $\left.2^{\text {nd }} e d\right)$. Ishiyaker Euro America: Inc. Publishers: 2000:384-385.

9. Joseph B.Breitman, Scott Nakamurer, Arnold L. Freedman and Irving L. Yalisove. Telescopic Retainers: An Old or New solution? A second chance to have normal Dental Function. J Prosthodont 2011; 21:7983.

10. Zitzman NU, Rohner $\mathrm{U}$, Weiger R, Krastl G. When to choose which retention element to use for removable dental prosthesis. Int J Prosthodont2009; 22:223-241.

11. Langer A. Combination of diverse retainers in removable partial dentures. J Prosthet Dent 1978; 40:378-384.

12. Misch CE. Dental implant prosthetics. Elsevier Mosby; 207p.

13. Watson RM. The role of removable prosthesis and implants in restoration of the worn dentition. Eur J Prosthodont Restor Dent 1997; 5:181-86. 